\title{
A cultura pop na contemporaneidade
}

\author{
Marcos Vinhas de Sousa
}

\section{SÁ, Simone Pereira; CARREIRO, Rodrigo; FERRARAZ, Rogerio (Org.) Cultura Pop. \\ Salvador/Brasília: Edufba/Compós, 296 p, 2015.}

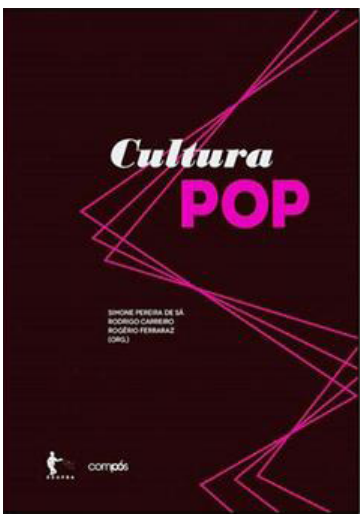

Resumo: O livro de ensaios Cultura Pop é uma contribuição importante para descobrir e entender a cultura pop como um universo simbólico composto por relações e sentidos fundamentais para pesquisas atuais sobre comunicação e mídia.

Palavras-chave: cultura pop; multiplicidade: mídias.

Abstract: Pop Culture in the contemporary age - Cultura Pop is an essay collection that brings an important contribution to the discovery and understanding of the pop culture as a symbolic universe composed by relations and meanings that are fundamental to current researches on communication and media.

Keywords: pop culture; multiplicity; media.

O que é cultura pop? O que pode ser classificado como cultura pop? Qual a importância da cultura pop? Essas perguntas e muitas outras são respondidas pelos quinze ensaios do livro intitulado, justamente, de Cultura Pop. Divididos em três partes, 
Por uma teoria da cultura pop, O pop como gênero midiático e A circulação do pop entre o global, o local e o periférico, os ensaios do livro parecem dialogar entre si e vão formando uma certa unidade que sempre transita entre conjunturas teóricas gerais e estudos de caso específicos. Essa combinação entre geral e específico fica explicitada ao se resumir os assuntos pesquisados por alguns ensaios aqui selecionados dessa coletânea.

A origem e a natureza do pop aparecem no ensaio Cultura pop: entre o popular e a distinção de Jeder Janotti Junior. A abertura do texto situa o assunto ao afirmar que:

A ideia de pop é carregada de acionamentos diferenciados e contradições. Rotular algo como pop pode servir tanto como uma adjetivação desqualificadora, destacando elementos descartáveis dos produtos midiáticos, bem como para afirmações de sensibilidades cosmopolitas, modos de habitar o mundo que relativizam o peso das tradições locais e projetam sensibilidades partilhadas globalmente (JANOTI, 2015, p. 47).

Janotti frisa como a cultura pop equaciona uma parte negativa de produção e consumo capitalista e uma parte positiva que torna possível um consumo globalizado e sensível. Ele acredita no poder das apropriações sensíveis dos consumidores através de ações que vão muito além de questões exclusivamente mercadológicas e que, por isso, conseguem transformar a cultura pop em uma zona de conflito na qual se reterritorializam linguagens e ferramentas da cultura.

As possibilidades de comunhão do pop são abordadas no ensaio Like a prayer: articulações da cultura na midiatização da religião de Luis Mauro Sá Martino (2015), que mostra como a fé religiosa é transfigurada pela cultura midiática do pop. Martino afirma que mais do que uma aproximação entre essas duas esferas, foi se organizando algo que pode ser chamado de cultura pop religiosa, o que ressalta como a religião e o pop estão sujeitos a crenças e vivências para se estabelecer. $\mathrm{O}$ ambiente midiático da cultura pop e o ambiente sacro da religião foram, simultaneamente, contaminando um ao outro, ou seja, a religião se articula na midiatização da cultura pop, que, por sua vez, se apropria de símbolos e temáticas religiosas.

As transições simbólicas atuais são tratadas no ensaio Celebridades do passinho: mídia, visibilidade e reconhecimento dos jovens na periferia de Cláudia Pereira, Aline Maia e Marcella Azevedo que analisam a dança do passinho, um desafio entre adolescentes de favelas cariocas que executam passos de dança que são dançados ao som de celulares, gravados, editados e postados no YouTube, uma plataforma de exibição de produções de mídias periféricas e de grandes mídias. As três autoras explicam que a sobreposição da cena midiática periférica com a popularização através de grandes mídias, mostra como a dança do passinho constrói-se em várias camadas que atingem até problemas sociais. 
A emergência do passinho, impulsionada por sua exposição midiática e apoio de grandes empresas, traz à tona figuras que se destacam no movimento, (...) aqueles que conquistam maior espaço na mídia contribuem para a constituição de novas representações de jovens da periferia, representações essas em sua maioria associadas a um cenário de violência e delinquência (PEREIRA, ALINE, AZEVEDO, 2015, p. 216).

Configurações econômicas e sociopolíticas são examinadas em Cultura pop e política na nova ordem global: lições do Extremo Oriente de Alfonso de Albuquerque e Krystal Cortez que mapeiam a emergência de determinados tipos de música pop japonesa e coreana do cenário asiático para o cenário global. O ensaio ressalta que o pop só se realiza através da heterogeneidade vinda de vários pólos de criação. Os diversos formatos de música pop foram criados em conjunto com ações mercadológicas para um consumo global, como foi o caso dos projetos japonês e coreano que visavam a saída dos chamados J-Pop e do K-Pop para países da Ásia e do resto mundo.

A seleção desses quatro ensaios enfatiza como a cultura pop é consumo e venda de produtos, mas, ao mesmo tempo, escolhas particulares e criações singulares. Como esclarecem os três organizadores da publicação, Simone Pereira de Sá, Rodrigo Carreiro e Rogerio Ferraraz, trata-se de driblar o senso comum:

Muito além do mercado, muito além do entretenimento, muito além do efêmero, muito além do clichê, da superficialidade e da despolitização, a cultura pop nos desafia [...] do conforto das fórmulas prontas e dos objetos canônicos (SÁ 2015, p. 14).

Marco Vinhas de Souza é doutor em Comunicação e Semiótica pela PUC-SP e pesquisador do Centro de Estudos Orientais da PUC-SP.

eugenidis@hotmail.com 